Infants who experience more adult-initiated conversations have better expressive language in toddlerhood

Virginia C. Salo ${ }^{1 *}$, Lucy S. King ${ }^{2}$, lan H. Gotlib², \& Kathryn L. Humphreys ${ }^{3}$

${ }^{1}$ Eunice Kennedy Shriver National Institute of Child Health and Human Development

${ }^{2}$ Stanford University, Department of Psychology

${ }^{3}$ Vanderbilt University, Department of Psychology and Human Development

Corresponding author:

Virginia C. Salo

Eunice Kennedy Shriver National Institute of Child Health and Human Development

National Institutes of Health

6710B Rockledge Drive

Bethesda, MD 20892

virginia.salo@nih.gov

(301) 402-3682

Keywords: caregivers; infancy; toddlerhood; language; naturalistic

Acknowledgements: We thank Emilia Cardenas, Regan Carell, Anna Cichocki, Kaitlyn Couch, Cheyenne Garcia, Mia Letterie, Amar Ojha, Hannah Piersiak, Francesca Querdasi, Marissa Roth, Lucinda Sisk, and Jillian Segarra for their assistance in data collection and management. We are grateful to our study participants for their time and trust in our research team. This work was supported by National Institutes of Health Grants R21 MH111978 and R21 HD090493 (to I.H.G.) and F32 HD100079 (to V.C.S.), the National Science Foundation Graduate Student Research Fellowship (L.S.K.), and the Jacobs Foundation Early Career Research Fellowship 2017-1261-05 (to K.L.H.). The authors declare no competing financial interests. The views expressed in this article are those of the authors and do not necessarily represent those of the National Institutes of Health, Eunice Kennedy Shriver National Institute of Child Health and Human Development, or the U.S. Department of Health and Human Services. 


\begin{abstract}
To understand how infants become engaged in conversations with their caregivers, we examined who tends to initiate conversations between adults and infants, differences between the features of infant- and adult-initiated conversations, and whether individual differences in how much infants engage in infant- or adult-initiated conversations uniquely predict later language development. We analyzed naturalistic adult-infant conversations captured via passive recording of the daily environment in two samples of 6 -month-old infants. In Study 1 , we found that at age 6 months, infants typically engage in more adult- than infant-initiated conversations and that adult-initiated conversations are, on average, longer and contain more adult words. In Study 2, we replicated these findings and, further, found that infants who engaged in more adult-initiated conversations in infancy had better expressive language at age 18 months. This association remained significant when accounting for the number of infantinitiated conversations at 6 months. Our findings indicate that early interactions with caregivers can have a lasting impact on children's language development, and that the extent to which parents initiate interactions with their infants may be particularly important.
\end{abstract}




\section{Infants who experience more adult-initiated conversations have better expressive language in toddlerhood}

Language develops in the context of social interactions composed of speakers and listeners (Bruner, 1981; Snow, 1972; Tomasello, 2008; Vygotsky, 1978). Both the quantity and quality of speech that adult caregivers offer young children during day-to-day verbal interactions reliably predict their later language abilities (Bornstein et al., 2020; Hoff, 2003; Huttenlocher, 1998; Huttenlocher et al., 1991, 2007; Pan et al., 2005; Rowe, 2012; Topping et al., 2013). Research examining early language exposure has often emphasized the number and the diversity of adult words that infants and young children experience (e.g., d'Apice et al., 2019). However, the number of verbal exchanges or "conversational turns"-that is, responsive and contingent back-and forth-utterances-in which children engage with adults appear to be particularly important for language development (Gilkerson et al., 2018; Zimmerman et al., 2009).

Theories of child development have increasingly embraced a dynamic interaction model in which children are active players in their environment (e.g., Sameroff \& Mackenzie, 2003); only recently, however, has this lens been used to examine the conversations that take place in early life. Research assessing parent responses to child-initiated interactions suggests that, across stages of early language development (e.g., understanding words, producing words, combining words into sentences), children whose parents provide appropriate and timely verbal responses when prompted by a change in their child's behavior develop greater competence (Tamis-LeMonda et al., 2006). Thus, by eliciting important parent-child interactions, children may contribute to their own language development. In fact, Lopez, Walle, Pretzer, \& Warlaumont (2020) found that infant-initiated conversations (i.e., infant vocalizations followed by caregiver responses) between 13-month-olds and their caregivers were positively associated with the infants' concurrent productive vocabulary. However, researchers have also found that the number of conversations between children and adults early in infancy (i.e., prior to age two 
years) do not predict later language skills (Gilkerson et al., 2018). Importantly, although researchers have suggested that it is important for caregivers to initiate conversations with their infants (Christakis et al., 2009; Zimmerman et al., 2009), previous research has not identified and distinguished who is initiating conversations between children and their caregivers in order to directly compare the qualities and predictive utility of child- versus adult-initiated conversations.

Understanding differences between adult- and infant-initiated interactions, as well as differences in the associations of these two types of interactions with language outcomes, may be particularly important in the first year of life. Around age 6 months, infants are highly dependent on adults to facilitate verbal interactions. Although infants at this age are starting to engage more frequently with their social world, they typically do not exhibit the signs of intentional communication that are likely to elicit responses from caregivers, such as gestures and words (Donnellan et al., 2020), and canonical syllables (containing at least one consonant and one vowel sound; Gros-Louis et al., 2016). In general, infants also tend to vocalize less than older children do (Gilkerson et al., 2017). For these reasons, caregivers may be less likely to respond to infants' vocalizations than they are to those of older children, and child-initiated conversations may be less common during the first year of life. Another important reason to consider infants' conversations at 6 months, despite differences in their verbal and communicative abilities, are findings that the number of conversational turns in which they engage is linked to individual differences in brain networks that are associated with language production and comprehension (King, Camacho, et al., 2021). Ultimately, although adultinitiated conversations are likely to be more prevalent during infancy than are infant-initiated conversations, we do not know which form of communication is associated most strongly with infants' language development. Understanding the relative contributions of adult- and infantinitiated conversations in infancy-a period of unparalleled brain development-to subsequent language development has important implications for determining recommendations for 
caregivers and for identifying features of the language environment that could be targeted in early interventions.

Across two studies, we compare the nature and amount of infant- and adult-initiated conversations at infant age 6 months and explore how these two types of infant-adult conversation uniquely predict subsequent language development. In Study 1 , in a sample of mother-infant dyads residing in the southeastern U.S., we explored whether adults or infants initiate a greater proportion of naturalistic conversations in infants' daily lives, as well as differences in the nature of adult- and infant-initiated conversations. Specifically, we examined whether adult- and infant-initiated conversations differ in the duration of the conversation, the number of "turns" within the conversation, and the number of adult words within the conversation. In Study 2, we sought to replicate and extend these findings in a second sample of mother-infant dyads residing in the northwestern U.S., in whom we also assessed child language abilities at age 18 months. In addition to testing whether differences in the proportion and nature of adult- and infant-initiated conversations observed in Study 1 are replicated in this second sample, we examined whether individual differences in patterns of conversations at infant age 6 months predicted subsequent vocabulary in toddlerhood.

\section{Study 1}

\section{Methods}

\section{Participants}

All procedures and recruitment methods were in accordance with the ethical standards of the American Psychological Association and approved by the Institutional Review Board of Vanderbilt University, and all participants provided informed consent prior to participating. Data for this study come from a larger study, with an initial visit in pregnancy, examining the association between early life experiences and infant development. Participants were recruited from the greater Nashville area from obstetrics clinics and through digital and print advertisements. Participants engaged in additional sessions during pregnancy and at infant age 
6 months that are outside the scope of the current paper. Inclusion criteria for the 6-month assessment were that mothers were at least 18 years of age and were fluent in English. Exclusion criteria included severe complications during birth, infant head trauma, infant premature birth (<36 weeks gestation), and infant congenital/genetic/neurological disorders. Of the 132 women who participated in the initial session during their pregnancy, 95 mother-infant dyads returned for the infant age 6-month follow-up. Of those, 20 did not complete a recording of the infant's language environment when the infant was approximately 6 months ( $\geq 5$ months, $<8$ months) and 3 completed their recordings when the infant was older than 8 months, yielding a final sample of 72 dyads. See Table 1 for detailed sample characteristics. Participants with missing data differed from those who were included in the final sample in terms of maternal employment status; see supplemental Table S3 for demographic statistics for those with missing data and Table $\mathbf{S 4}$ for a comparison of those with complete and missing data.

\section{Procedures}

Mothers provided informed written consent for themselves and their infants and were compensated for their time. When infants were approximately 6 months of age, dyads were provided with a Language ENvironment Analysis (LENA) digital processing device, specialized infant clothing for wearing the LENA device, and instructions that the infant wear the device from waking to bedtime on a typical day at home. The LENA device records for up to 16 hours. To be included in the current analyses, we required families to have completed the full 16 hours of recording and for the recording to have been completed when the infant was at least 5 months and less than 8 months of age.

\section{Measures}

Conversation Type. We extracted all of the conversations that took place between the target infant and an adult over the course of the recording using the LENA software (see Gilkerson \& Richards, 2020 for details regarding how the LENA algorithm defines all audio segments). Conversations are defined as comprising one or more alternation between the target 
infant (the infant wearing the LENA DLP) and an adult speaker, in which the infant produces speech-related vocalizations (i.e., cannot include only cries or vegetative sounds) and the adult produces at least vocalization. To be identified as a conversation, the speech segments must be separated by no more than five seconds of silence or other nonspeech. If another speaker interrupts within the five second allowed gap, the conversation is ended. After extracting all the conversations, we defined each conversation as either adult-initiated or infant-initiated by identifying the first speaker in that conversation.

Conversation Features. For each conversation, we also identified the duration of the conversation, the number of conversational turns, and the number of adult words. Duration of a conversation was the span of time from the start of the conversation-initiating vocalization segment to the end of the final vocalization segment. Conversational turns were the number of speaker alternations that took place during the conversation. Turns were only counted upon a response. For example, if in one conversation initiated by the infant, an adult responded and then the infant responded, that conversation would contain two conversational turns. Adult words were estimated number of words spoken by an adult during the conversation derived using acoustic information in the speech segment (Gilkerson \& Richards, 2020).

\section{Results}

All analyses were conducted in R version 4.0.2 (R Core Team, 2020). De-identified data and primary analysis scripts are available at https://github.com/vanderbiltsealab/6m_convos. Descriptive statistics for adult- and infant-initiated conversation are presented in Table 2. In total there were 12,481 conversations across the 72 infants. We found that, on average, infants engaged in more adult-initiated than infant-initiated conversations, $t(71)=10.16, p<.001, d=1.20$, $95 \% \mathrm{Cl}[0.90,1.51]$. Adult-initiated conversations made up approximately $58 \%$ of adult-infant conversations (Range: $40 \%-75 \%$ ).

Next, we examined differences in features of the conversations based on whether the conversation was adult- or infant-initiated. We used mixed-effects models to account for the 
nested nature of conversations occurring within individuals in which conversation type (dichotomous variable with adult-initiated conversations coded as 1 and infant-initiated as 0 ) was modeled as a fixed effect, accounting for the random effect of participant intercept. First, using a linear mixed-effects model, we tested whether the duration of the conversation differed based on whether it was initiated by an adult or an infant. Duration was significantly skewed (skew=13.33) and model residuals were not normally distributed; thus, we log-transformed this variable, yielding a more normal distribution (skew=0.23). We used log-transformed values in subsequent analyses. Second, using generalized linear mixed models with Poisson distributions (log link) for the dependent variable, we tested whether the number of conversational turns and the number of adult words within a conversation differed based on whether the conversation was initiated by an adult or an infant.

We present results of the models examining the associations between conversation type and each conversation feature in Table 3. Accounting for within-individual differences in the average number of conversations, adult-initiated conversations were longer and contained more adult words than did infant-initiated conversations. The incidence rate ratio parameters produced by the generalized linear mixed models can be interpreted such that the expected count of the dependent variable is multiplied by a factor of the incidence rate ratio when the independent variable increases from 0 to 1 . Thus, infants heard 2.35 times as many adult words in adult-initiated conversations as they did in infant-initiated conversations. There was also a small but statistically significant difference in the number of conversational turns based on conversation type: adult-initiated conversations contained more conversational turns. We provide a visual comparison of conversation features within infant-initiated and adult-initiated conversations in Figure 1. 


\section{Study 2}

\section{Methods}

\section{Participants}

All procedures and recruitment methods were in accordance with the ethical standards of the American Psychological Association and approved by the Institutional Review Board of Stanford University. Prior to participating, all mothers provided informed written consent for themselves and their infant. Dyads were compensated for their time. Participants were women and their infants who were recruited from communities in the San Francisco Bay Area to participate in the Brain and Behavior Infant Experiences (BABIES) project (Humphreys et al., 2018; King, Camacho, et al., 2021; King, Querdasi, et al., 2021), an observational study of the association between perinatal experiences and infant and toddler psychobiological development. Inclusion criteria for the 6-month assessment were that mothers had a singleton infant age 5-9 months, were at least 18 years of age, were fluent in English, and had no immediate plans to leave the geographic area. Exclusion criteria included severe complications during birth, infant head trauma, infant premature birth (prior to 36 weeks gestation), and infant congenital, genetic, or neurological disorders.

The sample for the current analyses included mother-infant dyads who completed a recording of the infant's language environment when the infant was approximately 6 months (infant assessment) and an online follow-up assessment of the infant's receptive and expressive vocabulary at age 17-21 months (toddler assessment). Of the 155 dyads who provided any data at the infant assessment, 36 did not participate in the LENA assessment and 17 did not provide usable LENA recordings for the naturalistic assessment of infants' environments (15 completed their recordings when infant was older than 8 months, 2 did not complete full recordings). Of those who provided useable LENA data, 13 did not complete the toddler assessment by the time of the current analysis, yielding a final sample of 89 dyads. Demographic statistics for the final sample are presented in Table 1. Participants with missing data did not differ from those 
included in the final sample in demographic variables; see supplemental Table $\mathbf{S 2}$ for demographic statistics for those with missing data and Table S3 for a comparison of those with complete and missing data. Further, participants who did and did not provide data at age 18 months did not differ significantly in terms of the measures derived from the LENA assessment at infant age 6 months; see supplemental Table S4 and Table S5.

\section{Procedures}

A subset of participants engaged in additional sessions during pregnancy and all participants provided completed additional tasks at infant age 6 months that are outside the scope of the current paper. Mothers provided informed written consent for themselves and their infants and were compensated for their time. As in Study 1, at the 6-month assessment motherinfant dyads were provided with a LENA digital processing device, specialized infant clothing, and instructions that the infant wear the device from waking to bedtime on a typical day at home. Again, families were required to have completed the full 16 hours possible of recording and for the recording to have been completed when the infant was at least 5 months and less than 8 months old to be included in the current analyses. At infant age 18 months, the infant's mother was asked to complete a series of questionnaires regarding the infant's development, including a measure of infant expressive and receptive vocabulary.

\section{Measures}

6-month Adult-Infant Conversations. The same measures were extracted from the LENA data in this study as were extracted in Study 1.

18-month Expressive and Receptive Vocabulary. Infants' expressive and receptive vocabulary skills were measured at 18-months via parent report using the short, toddler form of the MacArthur Communicative Developmental Inventories (Fenson et al., 2000). This form of the CDI provides a checklist of 100 words for parents to indicate whether their infant understands or understands and says each word. The total number of words a parent indicates that their infant understands serves as a measure of the infant's receptive vocabulary. Similarly, 
the total number of words a parent indicates their infant understands and says serves as a measure of the infant's expressive vocabulary.

\section{Results}

Comparisons of the two study samples on the primary variables of interest are presented in the Supplemental Materials. Descriptive statistics for each type of conversation are presented in Table 4. In total there were 18,245 conversations across the 89 infants. We conducted the same set of analyses as we did in Study 1, comparing differences in the quantity and features of conversations on the basis of whether the conversation was adult- or infant-initiated. Replicating the results obtained in Study 1, we found that, on average, infants engaged in more adultinitiated than infant-initiated conversations, $t(88)=9.30, p<.001, d=0.99,95 \% \mathrm{Cl}[0.73,1.24]$. Similar to Study 1, adult-initiated conversations comprised approximately $57 \%$ of all adult-infant conversations (Range: 39\%-79\%).

We then tested differences in features of the conversations based on who initiated the conversations. As in Study 1, we use mixed-effects models in which conversation type (dichotomous variable with adult-initiated conversations coded as 1 and infant-initiated as 0 ) was modeled as a fixed effect, controlling for the random effect of participant intercept. In the linear mixed-effects model testing whether duration of the conversation differed based on whether the conversation was adult- or infant-initiated, we again used a log-transformed duration variable to account for skewness (raw duration skew=5.81; log-transformed skew=0.21) and non-normal residuals. We also conducted generalized linear mixed models with Poisson distributions (log link) for the dependent variable to test whether the number of conversational turns or adult words within a conversation differed based on who initiated the conversation. Results of the models examining the associations between conversation type and conversation feature are presented in Table 5. Replicating the findings from Study 1, adultinitiated conversations were longer and contained more adult words, compared to infant-initiated conversations. As in Study 1, we again found a small but statistically significant difference in the 
number of conversational turns based on conversation type, such that adult-initiated conversations contained more conversational turns. A visual comparison of conversation features within each type of conversation can, again, be seen in Figure 1.

Lastly, we examined whether engaging in either type of conversation differentially predicts later language skills. At 18 months, mean parent-reported expressive vocabulary was 24.46 (SD=20.14, Range: 0-96) and mean parent-reported receptive vocabulary was 60.98 $(S D=21.64$, Range: $12-100)$. The mean age-normed percentile score for expressive vocabulary was 35.47 , with scores ranging from 0 to the $99^{\text {th }}$ percentile, suggesting this sample represented a wide range of relative language ability. We conducted a series of generalized linear models with quasi-Poisson distributions for the dependent variable to test whether the number of each type of conversation in which infants were engaged accounted for a significant proportion of the variance in subsequent language, either when considered as the sole predictor or when accounting for the other type of conversation. The quasi-Poisson distribution accommodates the nature of the dependent variables as counts as well as the observed overdispersion (variance greater than the mean).

We present the results of the models predicting expressive vocabulary in Table 6. Infants who engaged in more adult-initiated conversations at 6 months had significantly greater expressive vocabulary at 18 months. Similarly, infants who engaged in more infant-initiated conversations at 6 months had significantly greater expressive vocabulary at 18 months. When both adult- and infant-initiated conversations were included as statistical predictors of toddler expressive vocabulary, only adult-initiated conversations were significantly associated with 18month vocabulary. Specifically, a $1 \%$ increase in expressive vocabulary is predicted for every additional adult-initiated conversation the infant experienced. Results of the models predicting receptive vocabulary are presented in Table 7. Neither adult- nor infant-initiated conversations were associated with receptive vocabulary. Results of the models predicting expressive and receptive vocabulary with either adult-initiated or infant-initiated conversations as the sole 
predictor are depicted in Figure 2. A single multivariate outlier and potentially influential case was identified in the model predicting expressive vocabulary from infant-initiated conversations (operationalized as Cook's distance score >1). A corresponding model was computed removing that infant, which yielded a nonsignificant association between infant-initiated conversations and later expressive vocabulary $(p=.319)$. The model predicting expressive vocabulary including both adult- and infant-initiated conversations was conducted after removing the outlying infant; adult-initiated conversations remained a significant predictor of expressive vocabulary. No outliers were identified in any of the other models.

\section{Discussion}

Our goal across two studies was to understand how infants become engaged in conversations with their caregivers. Specifically, we examined who tends to initiate conversations between adults and infants, differences in the nature of infant- compared to adultinitiated conversations, and whether individual differences in how often infants are engaged in infant- or adult-initiated conversations uniquely predict subsequent language development. To achieve these goals, we analyzed adult-infant conversations captured via LENA digital recording devices in two samples of 6-month-old infants. In Study 1, we found in exploratory analyses that at age 6 months, infants typically engage in more adult- than infant-initiated conversations and that adult-initiated conversations are, on average, longer, involve more conversational turns, and contain more adult words. In Study 2, we replicated these findings and, further, found that infants who engaged in more adult-initiated conversations in infancy had better expressive language at age 18 months. While vocabulary at age 18 months was also significantly associated with infant-initiated conversations, when we accounted for both types of conversations as predictors, only the number of adult-initiated conversations at age 6 months was significantly associated with language skills one year later. Early interactions with caregivers can have a lasting impact on children's language development. These findings 
indicate that the extent to which parents initiate those interactions with their infants may be particularly impactful.

The finding that, on average, infants were engaged in more adult- than infant-initiated conversations at age 6 months is consistent with our prediction and is perhaps not surprising given that at this age infants are likely highly dependent on adults to facilitate verbal interactions. Further, the communicative behavior that 6-month-old infants exhibit is rarely viewed as intentionally communicative and, therefore, less likely to elicit responses from caregivers (Donnellan et al., 2020). Across both samples, $21-60 \%$ of an infant's conversations were infant-initiated, and only $9 \%$ of infants were involved in more infant- than adult-initiated conversations. Thus, regardless of the specific ratio, all infants in these studies were engaged in a large proportion of adult-initiated conversations throughout their day, emphasizing the need to understand the kind of input that infants experience during these interactions.

Interestingly, across both samples, conversation type (adult- versus infant-initiated) explained only a small (albeit statistically significant) portion of the variance in duration of conversations (3-4\%) and an even smaller, almost negligible, portion of the variance in the number of turns $(<1 \%)$ within a conversation. In contrast, conversation type explained almost half $(\sim 47 \%)$ of the variance in the number of adult words in a conversation. When an adult initiated a conversation, or-considered from the other perspective-when an infant responded to an adult's bid to begin a conversation, the infant experienced far more adult words than when the infant initiated a conversation. Relatedly, the conditional intraclass correlation (ICC) values derived from the mixed regression models indicate that individual (family-level) differences explain a much larger portion of the variance in the number of adult words that infants experience within conversations (45-46\%), than in the duration of $(4 \%)$ or conversational turns within $(5 \%)$ conversations. In other words, unmeasured characteristics of the infant or their family account for roughly the same amount of variance in the number of adult words an infant experiences in a conversation as does who is initiating that conversation. These findings 
suggest that beyond who is initiating the conversation, several unmeasured infant- and familylevel factors likely influence the nature of the input children receive in conversations with adults. The context in which an interaction occurs (e.g., book reading, toy play, mealtime, and dressing) is associated with different patterns in both parent and child communication (Hoff-Ginsberg, 1991; Yont et al., 2003), as is time of day (Soderstrom \& Wittebolle, 2013). Examining such additional characteristics as primary predictors of the quantity and quality of language used within caregiver-child conversations, as well as how they interact with the person who is initiating the conversation, would be a fruitful next step for explaining individual differences in language environments.

Although previous studies have not directly compared adult- versus child-initiated conversations, there is a growing body of research suggesting that engaging in conversations with adults in early life has a generally positive impact on language development (Lopez et al., 2020; Rowe \& Snow, 2020; Zimmerman et al., 2009). These early experiences are even linked to individual differences in brain networks associated with language production and understanding (King, Camacho, et al., 2021; Romeo, Leonard, et al., 2018; Romeo, Segaran, et al., 2018). The current findings provide evidence that differences in linguistic input, during even short conversational interactions with caregivers, lead to substantial cumulative differences in children's communicative experiences during early life, thus influencing their language development. Further, our results suggest that the positive impact of adult-infant conversations, at age 6 months, are driven by adult-initiated conversations. Null associations between conversations in infancy and later language skills observed in prior studies (Gilkerson et al., 2018) may be due to the fact that these studies did not differentiate between adult- and infantinitiated conversations.

The present results appear to contradict research emphasizing the importance for child language development of parents' responses to child communicative bids (Tamis-LeMonda et al., 2006). In fact, we did not find a significant relation between the number of infant-initiated 
conversations and later vocabulary after accounting for adult-initiated conversations. However, it is important to note that the current methodology—capturing adult-infant conversations via audio recording - limits our ability to examine the impact of conversations that might have been initiated by an adult's response to their infant's non-vocal behavior. While there is evidence that infant gestures (e.g., pointing) are more likely to elicit responses from caregivers if they are paired with a vocalization (Ger et al., 2018), the predictive significance of infant initiations might have increased if gestures or other behaviors were also measured as initiations of communicative exchanges (Donnellan et al., 2020). Given that the infants in the current study were only 6 months, shifts in eye gaze (e.g., directing gaze at a caregiver or at a toy) or reaching toward objects may be interpreted as communicative bids by caregivers, who then responded. Similarly, infants at this age may be sensitive to their caregivers' gaze shifts as signs of communicative intent (Csibra, 2010). Another possibility for why we did not observe a significant association between infant-initiated conversations and later vocabulary, but one that is beyond the scope of the current data, is that infants who experience greater adult-initiated conversations at 6 months develop stronger communicative skills prior to the onset of their first words and building their vocabulary. For example, these infants may develop greater use of gestures or pragmatic understanding, which in turn leads to the larger vocabularies we observed at 18 months.

It is further helpful to consider our results specifically in light of the developmental stage during which the language environment was assessed. At 6 months, infants produce fewer behaviors that are interpreted as intentional communicative bids (e.g., gestures, canonical syllables, and words) than do older infants. If caregiver-child conversations were observed at 9 or 12 months, for example, we might expect to see caregivers responding more often to infants' vocalizations and thus a greater proportion of conversations being initiated by infants. Even at 12 months, however, caregivers tend to verbally respond more often to infants' object-directed gestures (e.g., pointing) than to their object-directed vocalizations (Wu \& Gros-Louis, 2015), 
potentially attenuating a LENA-derived estimate of infant-initiated conversations even at that age. A recent analysis suggests that by 30 months, children are initiating significantly more conversations than are their caregivers (VanDam et al., 2022); however, the extent to which this is driven by differences in child vocalizations from age 6 to 30 months (either in number or kind), by caregivers responding to a greater proportion of child bids, or by a combination of these is unknown. In addition, prior research suggests that predictors of language outcomes depend on the age at which children are assessed. This is true when the predictors in question are child (Choi et al., 2021) or caregiver communicative behavior (Newman et al., 2015; Rowe, 2012). Thus, our findings may be specific to middle infancy.

In addition, an important limitation of the current findings is that conversations were defined solely in terms of timing of vocalizations (a response, or counter-vocalization, occurring within 5 seconds of the initial vocalization). While timeliness (typically considered as responding within a few seconds) is an important part of verbal responsiveness, so is semantic or pragmatic contingency (Tamis-LeMonda et al., 2014). That is, adult utterances that are related both semantically and temporally to a child's vocalizations appear to have the greatest impact on child language (McGillion et al., 2013). Thus, assessing the semantic match of responses to infant- or adult-initiated conversations may yield a more nuanced understanding of the impact of each type of conversation on language development, and may be one of the previously mentioned "unmeasured characteristics" that influence the nature and impact of conversation type. Further, we should note that the difference in the observed effect of conversation type on conversational turns and adult words may be due, in part, to differences in how reliably the automated LENA analysis identifies each metric. Efforts to validate the LENA measures against human coding suggest that the automated extraction of adult word count is more reliable than is the extraction of conversational turns (Cristia et al., 2020). Automated LENA identification of adult speech has also been reported to be more reliable than is the case for child or infant speech (Bulgarelli \& 
Bergelson, 2020), although counts of conversational turns have higher test retest reliability than do counts of adult words (Gilkerson et al., 2017).

Another limitation of the current methodology is that the automated LENA analysis does not distinguish among individual adult speakers. A large literature has examined caregiver characteristics that explain the number of words to which a child is exposed, without considering whether or not the input occurs within a certain type of conversation (e.g., age of caregiver (McDonald Culp et al., 1996; Rowe et al., 2005), caregiver knowledge of child development (Rowe, 2008), and caregiver educational attainment (Vernon-Feagans et al., 2020)). Many of the infants in our studies likely interacted with more than one adult during the day; however, examining individual caregiver-level predictors of adult engagement with the infant was beyond the scope of the current analyses. Important complements to this work will be to compare the current results with a similar analysis of manually coded linguistic interactions and to explore which factors might be related to adults' tendency either to initiate or respond in conversations with their child. Finally, it is important to couch these findings within the relatively homogeneous samples we recruited. The mothers who participated in the current studies were primarily White with at least a four-year college degree living in suburban or urban areas of the United States. There is a large body of research documenting differences in the home language environment across socioeconomic strata in the US (Golinkoff et al., 2019), although there is also wide variation in children's language experiences within socioeconomic strata (Sperry et al., 2018). It may be a uniquely WEIRD (Western, Educated, Industrialized, Rich, Democratic) notion to engage in "conversations" with an infant (Han, 2020). Thus, further investigation is warranted to explore the generalizability of these findings, both across families with different demographics backgrounds within the US and across different cultural groups outside of the US.

Despite these limitations, the present study is important in providing evidence across two unique samples that infants' experiences differ in infant- and adult-initiated conversations, and that engaging in adult-initiated conversations may be particularly important for later language 
development. Identifying unique patterns in the kind of input infants receive in adult- and infantinitiated conversations increases our understanding of the language experiences of typically developing infants in naturalistic settings. These findings have important implications for recommendations given to caregivers and for potential targets in approaches to early intervention, specifically emphasizing the importance of caregivers initiating verbal interactions with infants even before the emergence of infants' first words. However, caregiver-child interactions encompass much more than words and spoken conversational turns. An important next step will be to consider how the factors identified in the current study interact with other important characteristics of caregiver-child interactions to predict language outcomes. 


\section{References}

Bornstein, M. H., Putnick, D. L., Bohr, Y., Abdelmaseh, M., Lee, C. Y., \& Esposito, G. (2020). Maternal sensitivity and language in infancy each promotes child core language skill in preschool. Early Childhood Research Quarterly, 51, 483-489.

https://doi.org/10.1016/j.ecresq.2020.01.002

Bruner, J. (1981). The social context of language acquisition. Language \& Communication, 1 , $155-178$.

Bulgarelli, F., \& Bergelson, E. (2020). Look who's talking: A comparison of automated and human-generated speaker tags in naturalistic day-long recordings. Behavior Research Methods, 52(2), 641-653. https://doi.org/10.3758/s13428-019-01265-7

Choi, B., Wei, R., \& Rowe, M. L. (2021). Show, give, and point gestures across infancy differentially predict language development. Developmental Psychology, 57(6), 851-862. https://doi.org/10.1037/dev0001195

Christakis, D. A., Gilkerson, J., Richards, J. A., Zimmerman, F. J., Garrison, M. M., Xu, D., Gray, S., \& Yapanel, U. (2009). Audible television and decreased adult words, infant vocalizations, and conversational turns: A population-based study. Archives of Pediatrics and Adolescent Medicine, 163(6), 554-558. https://doi.org/10.1001/archpediatrics.2009.61

Cristia, A., Lavechin, M., Scaff, C., Soderstrom, M., Rowland, C., Räsänen, O., Bunce, J., \& Bergelson, E. (2020). A thorough evaluation of the Language Environment Analysis (LENA) system. Behavior Research Methods. https://doi.org/10.3758/s13428-020-01393-5

Csibra, G. (2010). Recognizing communicative intentions in infancy. Mind \& Language, 25(2), 141-168. https://doi.org/10.1111/j.1468-0017.2009.01384.x

d'Apice, K., Latham, R. M., \& von Stumm, S. (2019). A naturalistic home observational approach to children's language, cognition, and behavior. Developmental Psychology, 55(7), 1414-1427. https://doi.org/10.1037/dev0000733

Donnellan, E., Bannard, C., McGillion, M. L., Slocombe, K. E., \& Matthews, D. (2020). Infants' 
intentionally communicative vocalizations elicit responses from caregivers and are the best predictors of the transition to language: A longitudinal investigation of infants' vocalizations, gestures and word production. Developmental Science, 23(1), e12843.

https://doi.org/10.1111/desc.12843

Fenson, L., Pethick, S., Renda, C., Cox, J. L., Dale, P. S., \& Reznick, J. S. (2000). Short-form versions of the MacArthur Communicative Development Inventories. Applied Psycholinguistics, 21(01), 95-115. https://doi.org/10.1017/S0142716400001053

Ger, E., Altınok, N., Liszkowski, U., \& Küntay, A. C. (2018). Development of infant pointing from 10 to 12 months: The role of relevant caregiver responsiveness. Infancy, 23(5), 708-729. https://doi.org/10.1111/infa.12239

Gilkerson, J., \& Richards, J. A. (2020). A Guide to Understanding the Design and Purpose of the LENA® System.

Gilkerson, J., Richards, J. A., Warren, S. F., Montgomery, J. K., Greenwood, C. R., Kimbrough Oller, D., Hansen, J. H. L., \& Paul, T. D. (2017). Mapping the Early Language Environment Using All-Day Recordings and Automated Analysis. American Journal of Speech-Language Pathology, 26(2), 248-265. https://doi.org/10.1044/2016_AJSLP-15-0169

Gilkerson, J., Richards, J. A., Warren, S. F., Oller, D. K., Russo, R., \& Vohr, B. (2018). Language experience in the second year of life and language outcomes in late childhood. Pediatrics, 142(4), e20174276. https://doi.org/10.1542/peds.2017-4276

Golinkoff, R. M., Hoff, E., Rowe, M. L., Tamis-LeMonda, C. S., \& Hirsh-Pasek, K. (2019). Language Matters: Denying the Existence of the 30-Million-Word Gap Has Serious Consequences. Child Development, 90(3), 985-992. https://doi.org/10.1111/cdev.13128

Gros-Louis, J., West, M. J., \& King, A. P. (2016). The Influence of Interactive Context on Prelinguistic Vocalizations and Maternal Responses. Http://Dx.Doi.Org/10.1080/15475441.2015.1053563, 12(3), 280-294. https://doi.org/10.1080/15475441.2015.1053563 
Han, S. (2020). Mothering tongues: Anthropological perspectives on language and the motherinfant nexus. In R. Gowland \& S. Halcrow (Eds.), The Mother-Infant Nexus in Anthropology. Bioarchaeology and Social Theory (pp. 145-155). Springer, Cham. https://doi.org/10.1007/978-3-030-27393-4_8

Hoff-Ginsberg, E. (1991). Mother-child conversation in different social classes and communicative settings. Child Development, 62(4), 782-796. https://doi.org/10.1111/j.1467-8624.1991.tb01569.x

Hoff, E. (2003). The specificity of environmental influence: Socioeconomic status affects early vocabulary development via maternal speech. Child Development, 74(5), 1368-1378. https://doi.org/10.1111/1467-8624.00612

Humphreys, K. L., King, L. S., Choi, P., \& Gotlib, I. H. (2018). Maternal depressive symptoms, self-focus, and caregiving behavior. Journal of Affective Disorders, 238, 465-471. https://doi.org/10.1016/J.JAD.2018.05.072

Huttenlocher, J. (1998). Language input and language growth. Preventive Medicine, 27(2), 195199. https://doi.org/10.1006/pmed.1998.0301

Huttenlocher, J., Haight, W., Bryk, A., Seltzer, M., \& Lyons, T. (1991). Early vocabulary growth: Relation to language input and gender. Developmental Psychology, 27(2), 236-248. https://doi.org/10.1037/0012-1649.27.2.236

Huttenlocher, J., Vasilyeva, M., Waterfall, H. R., Vevea, J. L., \& Hedges, L. V. (2007). The varieties of speech to young children. Developmental Psychology, 43(5), 1062-1083. https://doi.org/10.1037/0012-1649.43.5.1062

King, L. S., Camacho, M. C., Montez, D. F., Humphreys, K. L., \& Gotlib, I. H. (2021). Naturalistic language input is associated with resting-state functional connectivity in infancy. The Journal of Neuroscience, 41(3), 424-434. https://doi.org/10.1523/JNEUROSCI.077920.2020

King, L. S., Querdasi, F. R., Humphreys, K. L., \& Gotlib, I. H. (2021). Dimensions of the 
language environment in infancy and symptoms of psychopathology in toddlerhood.

Developmental Science. https://doi.org/10.1111/desc.13082

Lopez, L. D., Walle, E. A., Pretzer, G. M., \& Warlaumont, A. S. (2020). Adult responses to infant prelinguistic vocalizations are associated with infant vocabulary: A home observation study. PLOS ONE, 15(11), e0242232. https://doi.org/10.1371/journal.pone.0242232

McDonald Culp, A., Osofsky, J. D., \& O’Brien, M. (1996). Language patterns of adolescent and older mothers and their one-year-old children: a comparison study. First Language, 16(46), 61-75. https://doi.org/10.1177/014272379601604604

McGillion, M. L., Herbert, J. S., Pine, J. M., Keren-Portnoy, T., Vihman, M. M., \& Matthews, D. E. (2013). Supporting early vocabulary development: What sort of responsiveness matters. IEEE Transactions on Autonomous Mental Development, 5(3), 240-248. https://doi.org/10.1109/TAMD.2013.2275949

Newman, R. S., Rowe, M. L., \& Bernstein Ratner, N. (2015). Input and uptake at 7 months predicts toddler vocabulary: the role of child-directed speech and infant processing skills in language development. Journal of Child Language, 1-16.

https://doi.org/10.1017/S0305000915000446

Pan, B. A., Rowe, M. L., Singer, J. D., \& Snow, C. E. (2005). Maternal correlates of growth in toddler vocabulary production in low-income families. Child Development, 76(4), 763-782. https://doi.org/10.1111/j.1467-8624.2005.00876.x

R Core Team. (2020). R: A language and environment for statistical computing. R Foundation for Statistical Computing.

Romeo, R. R., Leonard, J. A., Robinson, S. T., West, M. R., Mackey, A. P., Rowe, M. L., \& Gabrieli, J. D. E. (2018). Beyond the 30-million-word gap: Children's conversational exposure is associated with language-related brain function. Psychological Science, 29(5), 700-710. https://doi.org/10.1177/0956797617742725

Romeo, R. R., Segaran, J., Leonard, J. A., Robinson, S. T., West, M. R., Mackey, A. P., 
Yendiki, A., Rowe, M. L., \& Gabrieli, J. D. E. (2018). Language exposure relates to structural neural connectivity in childhood. The Journal of Neuroscience: The Official Journal of the Society for Neuroscience, 38(36), 7870-7877.

https://doi.org/10.1523/JNEUROSCI.0484-18.2018

Rowe, M. L. (2008). Child-directed speech: Relation to socioeconomic status, knowledge of child development and child vocabulary skill. Journal of Child Language, 35(1), 185-205. https://doi.org/10.1017/S0305000907008343

Rowe, M. L. (2012). A longitudinal investigation of the role of quantity and quality of childdirected speech in vocabulary development. Child Development, 83(5), 1762-1774. https://doi.org/10.1111/j.1467-8624.2012.01805.x

Rowe, M. L., Pan, B. A., \& Ayoub, C. (2005). Predictors of variation in maternal talk to children: A longitudinal study of low-income families. Parenting, 5(3), 259-283. https://doi.org/10.1207/s15327922par0503_3

Rowe, M. L., \& Snow, C. E. (2020). Analyzing input quality along three dimensions: Interactive, linguistic, and conceptual. Journal of Child Language, 47(1), 5-21. https://doi.org/10.1017/S0305000919000655

Sameroff, A. J., \& Mackenzie, M. J. (2003). Research strategies for capturing transactional models of development: The limits of the possible. Development and Psychopathology, 15(3), 613-640.

Snow, C. E. (1972). Mothers' speech to children learning language. Child Development, 43(2), 549. https://doi.org/10.2307/1127555

Soderstrom, M., \& Wittebolle, K. (2013). When do caregivers talk? The influences of activity and time of day on caregiver speech and child vocalizations in two childcare environments. PloS One, 8(11), e80646. https://doi.org/10.1371/journal.pone.0080646

Sperry, D. E., Sperry, L. L., \& Miller, P. J. (2018). Reexamining the Verbal Environments of Children From Different Socioeconomic Backgrounds. Child Development. 
https://doi.org/10.1111/cdev.13072

Tamis-LeMonda, C. S., Cristofaro, T. N., Rodriguez, E. T., \& Bornstein, M. H. (2006). Early language development: Social influences in the first years of life. In L. Balter \& C. S. TamisLemonda (Eds.), Child psychology: A handbook of contemporary issues (pp. 79-108). Psychology Press.

Tamis-LeMonda, C. S., Kuchirko, Y., \& Song, L. (2014). Why Is infant language learning facilitated by parental responsiveness? Current Directions in Psychological Science, 23(2), 121-126. https://doi.org/10.1177/0963721414522813

Tomasello, M. (2008). Origins of human communication. MIT Press.

Topping, K., Dekhinet, R., \& Zeedyk, S. (2013). Parent-infant interaction and children's language development. In Educational Psychology (Vol. 33, Issue 4, pp. 391-426). Routledge. https://doi.org/10.1080/01443410.2012.744159

VanDam, M., Thompson, L., Wilson-Fowler, E., Campanella, S., Wolfenstein, K., \& De Palma, P. (2022). Conversation Initiation of Mothers, Fathers, and Toddlers in their Natural Home Environment. Computer Speech \& Language, 73, 101338.

https://doi.org/10.1016/J.CSL.2021.101338

Vernon-Feagans, L., Bratsch-Hines, M., Reynolds, E., \& Willoughby, M. (2020). How early maternal language input varies by race and education and predicts later child language. Child Development, 91(4), 1098-1115. https://doi.org/10.1111/cdev.13281

Vygotsky, L. S. (1978). Mind in society: The development of higher psychological processes. Harvard University Press.

Wu, Z., \& Gros-Louis, J. (2015). Caregivers provide more labeling responses to infants' pointing than to infants' object-directed vocalizations. Journal of Child Language, 42(3), 538-561. https://doi.org/10.1017/S0305000914000221

Yont, K. M., Snow, C. E., \& Vernon-Feagans, L. (2003). The role of context in mother-child interactions: an analysis of communicative intents expressed during toy play and book 
reading with 12-month-olds. Journal of Pragmatics, 35(3), 435-454.

https://doi.org/10.1016/S0378-2166(02)00144-3

Zimmerman, F. J., Gilkerson, J., Richards, J. A., Christakis, D. A., Xu, D., Gray, S., \& Yapanel, U. (2009). Teaching by listening: The importance of adult-child conversations to language development. Pediatrics, 124(1), 342-349. https://doi.org/10.1542/peds.2008-2267 
Table 1. Study 1 and Study 2 sample demographics

\begin{tabular}{|c|c|c|}
\hline & $\begin{array}{l}\text { Study } 1 \\
(N=72)\end{array}$ & $\begin{array}{l}\text { Study } 2 \\
(N=89)\end{array}$ \\
\hline $\begin{array}{l}\text { Infant Age at LENA recording } \\
\text { Mean (SD) months }\end{array}$ & $6.59(0.54)$ & $6.56(0.54)$ \\
\hline \multicolumn{3}{|l|}{$\begin{array}{l}\text { Infant Race } \\
\text { Number (percent) }\end{array}$} \\
\hline White & $61(85 \%)$ & $55(62 \%)$ \\
\hline American Indian/Alaska Native & $1(1 \%)$ & $0(0 \%)$ \\
\hline Asian/ Asian American & $0(0 \%)$ & $14(16 \%)$ \\
\hline Black/African American & $7(10 \%)$ & $2(2 \%)$ \\
\hline Native Hawaiian/Pacific Islander & $1(1 \%)$ & $1(1 \%)$ \\
\hline Other & $2(3 \%)$ & $17(19 \%)$ \\
\hline \multicolumn{3}{|l|}{$\begin{array}{l}\text { Infant Ethnicity } \\
\text { Number (percent) }\end{array}$} \\
\hline Hispanic or Latinx & $5(7 \%)$ & $13(15 \%)$ \\
\hline \multicolumn{3}{|l|}{$\begin{array}{l}\text { Infant Sex } \\
\text { Number (percent) }\end{array}$} \\
\hline Male & $33(46 \%)$ & $45(51 \%)$ \\
\hline \multicolumn{3}{|l|}{$\begin{array}{l}\text { Maternal Education } \\
\text { Number (percent) }\end{array}$} \\
\hline High School Diploma/GED & $6(8 \%)$ & $0(0 \%)$ \\
\hline Some College & $4(6 \%)$ & $7(8 \%)$ \\
\hline Associate's Degree & $5(7 \%)$ & $0(0 \%)$ \\
\hline Trade/Technical School & $0(0 \%)$ & $1(1 \%)$ \\
\hline Bachelor's Degree & $24(33 \%)$ & $30(34 \%)$ \\
\hline Graduate Degree & $33(46 \%)$ & $51(57 \%)$ \\
\hline \multicolumn{3}{|l|}{$\begin{array}{l}\text { Maternal Marital Status } \\
\text { Number (percent) }\end{array}$} \\
\hline Married/Domestic Partnership & $60(84 \%)$ & $82(92 \%)$ \\
\hline Single, never married & $11(15 \%)$ & $6(7 \%)$ \\
\hline Divorced & $1(1 \%)$ & $0(0 \%)$ \\
\hline Not Reported/Other & $0(0 \%)$ & $1(1 \%)$ \\
\hline \multicolumn{3}{|l|}{$\begin{array}{l}\text { Maternal Employment Status } \\
\text { Number (percent) }\end{array}$} \\
\hline Employed for wages & $45(62 \%)$ & $48(54 \%)$ \\
\hline Homemaker & $9(13 \%)$ & $23(26 \%)$ \\
\hline Out of work, looking for work & $3(4 \%)$ & $2(2 \%)$ \\
\hline Out of work, not looking for work & $11(15 \%)$ & $7(8 \%)$ \\
\hline Self-employed & $2(3 \%)$ & $6(7 \%)$ \\
\hline Student & $2(3 \%)$ & $1(1 \%)$ \\
\hline Not Reported/Other & $0(0 \%)$ & $2(2 \%)$ \\
\hline
\end{tabular}




$\$ 5,001-15,000$
$\$ 15,001-30,000$
$\$ 30,001-60,000$
$\$ 60,001-90,000$
$\$ 90,001-150,000$
More than $\$ 150,000$

Children ( $\leq 17$ years) in the home Number (percent)

1

2

3

4

5

$\begin{array}{cc}0(0 \%) & 1(1 \%) \\ 3(4 \%) & 1(1 \%) \\ 13(19 \%) & 12(14 \%) \\ 21(29 \%) & 6(7 \%) \\ 24(33 \%) & 25(28 \%) \\ 11(15 \%) & 44(49 \%)\end{array}$

$32(44 \%)$

$50(56 \%)$

$31(43 \%)$

$8(12 \%)$

$28(32 \%)$

$8(9 \%)$

$1(1 \%)$

$2(2 \%)$ 
Table 2. Study 1 descriptive statistics for adultinitiated and infant-initiated conversations

\begin{tabular}{|c|c|c|}
\hline & Adult Initiated & Infant Initiated \\
\hline & \multicolumn{2}{|c|}{$\begin{array}{l}\text { Mean (SD) } \\
\text { Range }\end{array}$} \\
\hline $\begin{array}{l}\text { Total count across the } \\
\text { day }\end{array}$ & $\begin{array}{l}100.51 \\
(44.91) \\
13-215\end{array}$ & $\begin{array}{l}72.83 \\
(34.79) \\
10-186\end{array}$ \\
\hline $\begin{array}{l}\text { Duration of each } \\
\text { conversation } \\
\text { (seconds) }\end{array}$ & $\begin{array}{l}31.15 \\
(50.00) \\
1.40-2,070.56\end{array}$ & $\begin{array}{l}18.92 \\
(25.07) \\
1.41-469.26\end{array}$ \\
\hline $\begin{array}{l}\text { Count of } \\
\text { turns in each } \\
\text { conversation }\end{array}$ & $\begin{array}{l}1.73 \\
(1.94) \\
1-49\end{array}$ & $\begin{array}{l}1.57 \\
(1.57) \\
1-30\end{array}$ \\
\hline $\begin{array}{l}\text { Count of adult } \\
\text { words in each } \\
\text { conversation }\end{array}$ & $\begin{array}{l}56.92 \\
(135.78) \\
1-6,870\end{array}$ & $\begin{array}{l}23.34 \\
(47.36) \\
1-959\end{array}$ \\
\hline
\end{tabular}

Note. Statistics derived from raw data. 
Table 3. Results of Study 1 mixed models examining differences in features of conversations based on whether the conversation was adult- or infant-initiated

\begin{tabular}{|c|c|c|c|c|c|c|c|c|c|}
\hline \multirow[b]{2}{*}{ Predictors } & \multirow[b]{2}{*}{$B$} & \multicolumn{2}{|c|}{ Duration } & \multicolumn{3}{|c|}{ Conversational Turns } & \multicolumn{3}{|c|}{ Adult Words } \\
\hline & & $\mathrm{Cl}$ & $p$ & $\begin{array}{c}\text { Incidence } \\
\text { Rate } \\
\text { Ratios } \\
\end{array}$ & $\mathrm{Cl}$ & $p$ & $\begin{array}{c}\text { Incidence } \\
\text { Rate } \\
\text { Ratios }\end{array}$ & $\mathrm{Cl}$ & $p$ \\
\hline (Intercept) & 2.47 & $\begin{array}{l}2.41 \\
2.52\end{array}$ & $<.001$ & 1.51 & $\begin{array}{l}1.45 \\
1.58\end{array}$ & $<.001$ & 21.39 & $\begin{array}{l}19.44 \\
23.53\end{array}$ & $<.001$ \\
\hline $\begin{array}{l}\text { Conversation } \\
\text { Type }\end{array}$ & 0.41 & $\begin{array}{l}0.37 \\
0.44\end{array}$ & $<.001$ & 1.09 & $\begin{array}{l}1.07 \\
1.12\end{array}$ & $<.001$ & 2.35 & $\begin{array}{l}2.34 \\
2.37\end{array}$ & $<.001$ \\
\hline \multicolumn{10}{|l|}{ Random Effects } \\
\hline$\sigma^{2}$ & 0.95 & & & 0.49 & & & 0.03 & & \\
\hline $\mathrm{T}_{00}$ & 0.04 ID & & & $0.03 \mathrm{ID}$ & & & $0.18 \mathrm{ID}$ & & \\
\hline$I C C_{\text {adjusted }}$ & 0.04 & & & 0.05 & & & 0.87 & & \\
\hline ICC $\mathrm{Conditional}_{\text {. }}$ & 0.04 & & & 0.05 & & & 0.45 & & \\
\hline $\mathrm{N}$ & $72 \mathrm{ID}$ & & & $72 \mathrm{ID}$ & & & $72 \mathrm{ID}$ & & \\
\hline Observations & 12,481 & & & 12,481 & & & 12,481 & & \\
\hline $\begin{array}{l}\text { Marginal } R^{2} / \\
\text { Conditional } R^{2}\end{array}$ & $\begin{array}{l}0.039 / \\
0.076\end{array}$ & & & $\begin{array}{l}0.004 / \\
0.055\end{array}$ & & & $\begin{array}{l}0.477 / \\
0.931\end{array}$ & & \\
\hline
\end{tabular}

Note. Model of duration is a linear mixed model utilizing the log-transformed dependent variable. Models of conversational turns and adult words are generalized linear mixed models with Poisson (log link) distributions. 
Table 4. Study 2 descriptive statistics for adultinitiated and infant-initiated conversations

\begin{tabular}{|c|c|c|}
\hline & Adult Initiated & Infant Initiated \\
\hline & \multicolumn{2}{|c|}{$\begin{array}{l}\text { Mean (SD) } \\
\text { Range }\end{array}$} \\
\hline $\begin{array}{l}\text { Total count across the } \\
\text { day }\end{array}$ & $\begin{array}{l}116.38 \\
(40.72) \\
16-239\end{array}$ & $\begin{array}{l}88.62 \\
(32.19) \\
22-178\end{array}$ \\
\hline $\begin{array}{l}\text { Duration of each } \\
\text { conversation } \\
\text { (seconds) }\end{array}$ & $\begin{array}{l}32.17 \\
(45.90) \\
1.40-755.13\end{array}$ & $\begin{array}{l}20.15 \\
(26.10) \\
1.40-466.38\end{array}$ \\
\hline $\begin{array}{l}\text { Count of } \\
\text { turns in each } \\
\text { conversation }\end{array}$ & $\begin{array}{l}1.81 \\
(2.04) \\
1-48\end{array}$ & $\begin{array}{l}1.60 \\
(1.45) \\
1-21\end{array}$ \\
\hline $\begin{array}{l}\text { Count of adult } \\
\text { words in each } \\
\text { conversation }\end{array}$ & $\begin{array}{l}58.84 \\
(113.86) \\
1-2,323\end{array}$ & $\begin{array}{l}24.05 \\
(50.76) \\
1-1,613\end{array}$ \\
\hline
\end{tabular}

Note. Statistics derived from raw data. 
Table 5. Results of Study 2 mixed models examining differences in features of conversations based on whether the conversation was adult- or infant-initiated

\begin{tabular}{|c|c|c|c|c|c|c|c|c|c|}
\hline \multirow[b]{2}{*}{ Predictors } & \multirow[b]{2}{*}{$B$} & \multicolumn{2}{|c|}{ Duration } & \multicolumn{3}{|c|}{ Conversational Turns } & \multicolumn{3}{|c|}{ Adult Words } \\
\hline & & $\mathrm{Cl}$ & $p$ & $\begin{array}{c}\text { Incidence } \\
\text { Rate } \\
\text { Ratios }\end{array}$ & $\mathrm{Cl}$ & $p$ & $\begin{array}{c}\text { Incidence } \\
\text { Rate } \\
\text { Ratios }\end{array}$ & $\mathrm{Cl}$ & $p$ \\
\hline (Intercept) & 2.52 & $\begin{array}{l}2.48 \\
2.57\end{array}$ & $<.001$ & 1.56 & $\begin{array}{l}1.51 \\
1.62\end{array}$ & $<.001$ & 22.95 & $\begin{array}{l}21.12 \\
24.93\end{array}$ & $<.001$ \\
\hline $\begin{array}{l}\text { Conversation } \\
\text { Type }\end{array}$ & 0.37 & $\begin{array}{l}0.34 \\
0.40\end{array}$ & $<.001$ & 1.12 & $\begin{array}{l}1.09 \\
1.14\end{array}$ & $<.001$ & 2.27 & $\begin{array}{l}2.26 \\
2.28\end{array}$ & $<.001$ \\
\hline \multicolumn{10}{|l|}{ Random Effects } \\
\hline$\sigma^{2}$ & 0.97 & & & 0.47 & & & 0.03 & & \\
\hline $\mathrm{T}_{00}$ & 0.04 ID & & & $0.03 \mathrm{ID}$ & & & $0.16_{\mathrm{ID}}$ & & \\
\hline$I C C_{\text {adjusted }}$ & 0.04 & & & 0.05 & & & 0.86 & & \\
\hline $\mathrm{ICC}_{\text {conditional }}$ & 0.04 & & & 0.05 & & & 0.46 & & \\
\hline $\mathrm{N}$ & $89 \mathrm{ID}$ & & & $89 \mathrm{ID}$ & & & $89 \mathrm{ID}$ & & \\
\hline Observations & 18,245 & & & 18,245 & & & 18,245 & & \\
\hline $\begin{array}{l}\text { Marginal } R^{2} / \\
\text { Conditional } R^{2}\end{array}$ & $\begin{array}{l}0.032 / \\
0.074\end{array}$ & & & $\begin{array}{l}0.006 / \\
0.058\end{array}$ & & & $\begin{array}{l}0.473 / \\
0.928\end{array}$ & & \\
\hline
\end{tabular}

Note. Model of duration is a linear mixed model utilizing the log-transformed dependent variable. Models of conversational turns and adult words are generalized linear mixed models with Poisson (log link) distributions. 
Table 6. Results of generalized linear models predicting 18-month expressive vocabulary from count of adult- and infant-initiated conversations at 6 months

\begin{tabular}{|c|c|c|c|c|c|c|c|c|c|}
\hline \multirow[b]{2}{*}{ Predictors } & \multicolumn{3}{|l|}{ Incidence } & \multicolumn{3}{|l|}{ Incidence } & \multicolumn{3}{|l|}{ Incidence } \\
\hline & $\begin{array}{l}\text { Rate } \\
\text { Ratios }\end{array}$ & $\mathrm{Cl}$ & $p$ & $\begin{array}{c}\text { Rate } \\
\text { Ratios }\end{array}$ & $\mathrm{Cl}$ & $p$ & $\begin{array}{c}\text { Rate } \\
\text { Ratios }\end{array}$ & $\mathrm{Cl}$ & $p$ \\
\hline (Intercept) & 11.06 & $\begin{array}{l}6.75 \\
17.91\end{array}$ & $<.001$ & 15.33 & $\begin{array}{l}9.25 \\
24.99\end{array}$ & $<.001$ & 11.59 & $\begin{array}{l}6.88 \\
19.26\end{array}$ & $<.001$ \\
\hline $\begin{array}{l}\text { Count of } \\
\text { adult-initiated } \\
\text { conversations }\end{array}$ & 1.01 & $\begin{array}{l}1.00 \\
1.01\end{array}$ & $<.001$ & & & & 1.01 & $\begin{array}{l}1.00 \\
1.01\end{array}$ & .006 \\
\hline $\begin{array}{l}\text { Count of } \\
\text { infant-initiated } \\
\text { conversations }\end{array}$ & & & & 1.01 & $\begin{array}{l}1.00 \\
1.01\end{array}$ & .047 & 1.00 & $\begin{array}{l}0.99 \\
1.00\end{array}$ & .575 \\
\hline $\mathrm{R}^{2}$ Nagelkerke & 0.843 & & & 0.495 & & & 0.850 & & \\
\hline
\end{tabular}

Note. $\mathrm{N}=89$, models are generalized linear models utilizing quasi-Poisson distributions. 
Table 7. Results of generalized linear models predicting 18-month receptive vocabulary from count of adult- and infant-initiated conversations at 6 months

\begin{tabular}{|c|c|c|c|c|c|c|c|c|c|}
\hline Predictors & $\begin{array}{l}\text { Incidence } \\
\text { Rate } \\
\text { Ratios } \\
\end{array}$ & $\mathrm{Cl}$ & $p$ & $\begin{array}{c}\text { Incidence } \\
\text { Rate } \\
\text { Ratios } \\
\end{array}$ & $\mathrm{Cl}$ & $p$ & $\begin{array}{l}\text { Incidence } \\
\text { Rate } \\
\text { Ratios } \\
\end{array}$ & $\mathrm{Cl}$ & $p$ \\
\hline (Intercept) & 52.07 & $\begin{array}{l}41.51 \\
65.14\end{array}$ & $<.001$ & 56.10 & $\begin{array}{l}44.99 \\
69.70\end{array}$ & $<.001$ & 52.81 & $\begin{array}{l}41.55 \\
66.91\end{array}$ & $<.001$ \\
\hline $\begin{array}{l}\text { Count of } \\
\text { adult-initiated } \\
\text { conversations }\end{array}$ & 1.00 & $\begin{array}{l}1.00 \\
1.00\end{array}$ & .146 & & & & 1.00 & $\begin{array}{l}1.00 \\
1.00\end{array}$ & .206 \\
\hline $\begin{array}{l}\text { Count of } \\
\text { infant-initiated } \\
\text { conversations }\end{array}$ & & & & 1.00 & $\begin{array}{l}1.00 \\
1.00\end{array}$ & .427 & 1.00 & $\begin{array}{l}1.00 \\
1.00\end{array}$ & .712 \\
\hline $\mathrm{R}^{2}$ Nagelkerke & 0.168 & & & 0.054 & & & 0.178 & & \\
\hline
\end{tabular}

Note. $\mathrm{N}=89$, models are generalized linear models utilizing quasi-Poisson distributions. 


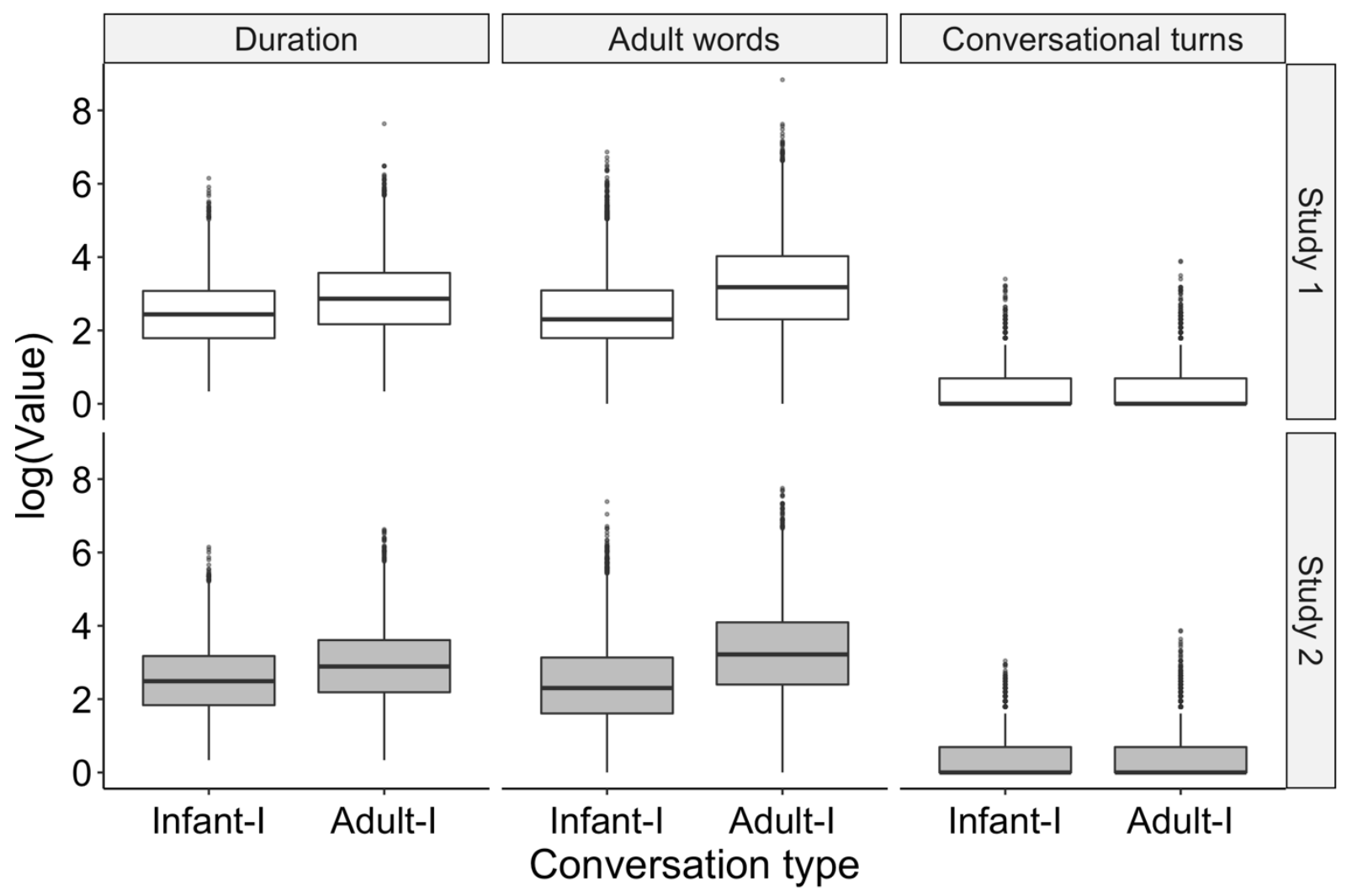

Figure 1. Box-plots of the features (duration, count of adult words, and count of conversational turns) of infant-initiated (Infant-I) and adult-initiated (Adult-I) conversations observed in Study 1 and Study 2. Feature values have been log transformed to align with presented analyses. The black bar represents the median value, and the lower and upper box boundaries mark the $25^{\text {th }}$ and $75^{\text {th }}$ percentiles, respectively. Filled circles represent data points beyond 1.5 times the interquartile range. 

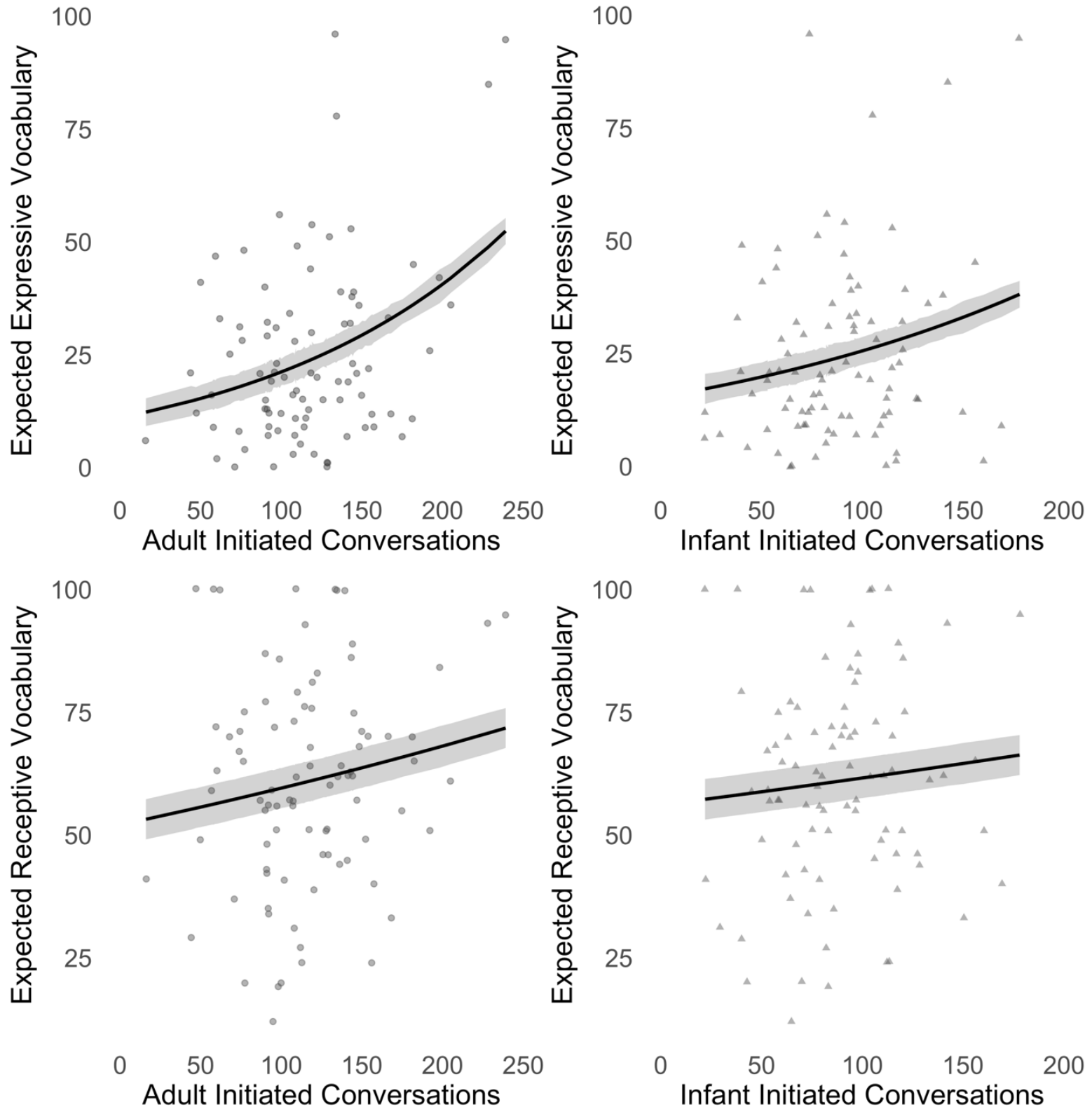

$\begin{array}{llll}50 & 100 & 150 & 200 \\ \text { Adult Initiated Conversations }\end{array}$

0
Infant Initiated Conversations

Figure 2. Associations between the number of adult- or infant-initiated conversations infants were engaged in at 6 months and their expressive or receptive vocabulary at 18 months. Black lines plot the model predicted vocabulary scores, with the $95 \%$ confidence interval represented by the shaded ribbon. Individual data points indicate the raw observed values. 


\section{Supplemental Material}

We examined whether the two study samples differed on the primary variables of interest. A series of independent-samples $t$-tests conducted to compare the two study groups in terms of number of adult- and infant-initiated conversations yielded significant differences in the average number of adult-initiated conversations, $t(145.06)=2.32, p=.022, d=0.37,95 \% \mathrm{Cl}[0.06$, 0.68], and infant-initiated conversations, $t(146.63)=2.96, p=.004, d=0.47,95 \% \mathrm{Cl}[0.16,0.79]$. Next, we conducted a series of mixed models predicting duration, conversational turns count, and adult word count within each conversation across the two study samples (as a dichotomous variable with Study 1 coded as 0 and Study 2 as 1 ). The log-transformed variable for duration was used in the linear mixed-effects model comparing duration across studies. Generalized linear mixed models with Poisson distributions (log link) for the dependent variable were used to compare conversational turns and adult words across studies. Results of the model, presented in Table S1, indicate that conversations were, on average, longer in Study 2 than in Study 1, and that individuals in Study 2 produced overall more conversational turns than did individuals in Study 1.

Sample demographics for individuals with missing data in both studies are presented in Table S2. In Study 1, 23 participants did not provide a LENA recording or their LENA recording did not meet study criteria (in terms of duration and child age). In Study 2, 53 participants did not provide LENA data (or their LENA recording did not meet study criteria), and 13 did not provide vocabulary data at 18 months. Several $\chi^{2}$ tests were conducted to explore whether the composition of these groups was similar to those in the final samples. Results of these tests are presented in Table S3. In Study 1, the proportions differed significantly by sample only for maternal employment status. Study 2 analyses compare the final sample with a combined group of all participants with missing data to account for the small number of individuals with missing MCDI data at 18 months. Individuals with missing data in Study 2 did not differ significantly from those included in the final sample on any demographic variables. 
Table S4 presents descriptive statistics for the primary study variables for those participants in Study 2 who did not provide vocabulary data at 18 months. We conducted a series of independent-samples t-tests comparing participants in Study 2 who were in the final sample with those who did not provide vocabulary data at 18 months with respect to number of adult- and infant-initiated conversations. These analyses yielded no significant differences in the average number of adult-initiated conversations, $t(15.5)=1.96, p=.068, d=0.59,95 \% \mathrm{Cl}[0.01$, 1.18], or in the average number of infant-initiated conversations, $t(15.11)=1.64, p=.121, d=0.52$, $95 \% \mathrm{Cl}[-0.07,1.11]$. Next, we conducted a series of mixed models predicting duration, conversational turns count, and adult word count within each conversation across the two groups of participants (as a dichotomous variable with Final Sample coded as 0 and Missing MCDI as 1). We used the log-transformed variable for duration in the linear mixed-effects model comparing duration across samples. We used generalized linear mixed models with Poisson distributions (log link) for the dependent variable to compare conversational turns and adult words across studies. These analyses, presented in Table S5, yielded no significant group differences. 
Table S1. Results of mixed models examining differences in features of conversations based on study sample.

\begin{tabular}{lcccccccccc}
\hline & & Duration & \multicolumn{3}{c}{ Conversational Turns } & \multicolumn{3}{c}{ Adult Words } \\
Predictors & Estimates & $C l$ & $p$ & $\begin{array}{c}\text { Incidence } \\
\text { Rate Ratios }\end{array}$ & $\mathrm{Cl}$ & $p$ & $\begin{array}{c}\text { Rate } \\
\text { Ratios }\end{array}$ & $\mathrm{Cl}$ & $p$ \\
\hline Intercept) & 2.68 & 2.63, & $<.001$ & 1.56 & 1.50, & $<.001$ & 38.43 & 35.89, & $<.001$ \\
& & 2.73 & & & 1.62 & & & 41.15 & \\
Site & 0.07 & 0.01, & .022 & 1.09 & 1.04, & $<.001$ & 1.01 & 1.00, & .158 \\
& & 0.13 & & & 1.14 & & & 1.02 &
\end{tabular}

\begin{tabular}{llll} 
Random Effects & & & \\
$\sigma^{2}$ & 1.00 & 0.48 & 0.03 \\
$\mathrm{~T}_{00}$ & $0.05 \mathrm{ID}$ & $0.03 \mathrm{ID}$ & $0.19 \mathrm{ID}$ \\
$\mathrm{ICC}$ conditional & 0.05 & 0.06 & 0.88 \\
$\mathrm{~N}$ & $156_{\mathrm{ID}}$ & $156_{\mathrm{ID}}$ & $156_{\mathrm{ID}}$ \\
\hline Observations & 30,726 & 30,726 & 30,726 \\
Marginal $\mathrm{R}^{2} /$ & $0.001 /$ & $0.003 /$ & $0.000 /$ \\
Conditional $\mathrm{R}^{2}$ & 0.046 & 0.057 & 0.880 \\
\hline
\end{tabular}

Note. Model of duration is a linear mixed model utilizing the log-transformed dependent variable.

Models of conversational turns and adult words are generalized linear mixed models with

Poisson (log link) distributions. 
Table S2. Demographics for individuals with missing data.

\begin{tabular}{|c|c|c|c|c|c|}
\hline & \multicolumn{2}{|c|}{ Study 1} & \multicolumn{3}{|c|}{ Study 2} \\
\hline & $\begin{array}{c}\text { Final } \\
\text { Sample } \\
(N=72)\end{array}$ & $\begin{array}{c}\text { Missing } \\
\text { LENA } \\
(\mathrm{N}=23)\end{array}$ & $\begin{array}{l}\text { Final } \\
\text { Sample } \\
(N=89)\end{array}$ & $\begin{array}{l}\text { Missing } \\
\text { LENA } \\
(N=53)\end{array}$ & $\begin{array}{c}\text { Missing } \\
\text { MCDI } \\
(N=13)\end{array}$ \\
\hline $\begin{array}{l}\text { Infant Age at LENA recording } \\
\text { Mean (SD) months }\end{array}$ & $6.59(0.54)$ & $\mathrm{N} / \mathrm{A}$ & $6.56(0.54)$ & $N / A$ & $6.37(0.43)$ \\
\hline \multicolumn{6}{|l|}{$\begin{array}{l}\text { Infant Race } \\
\text { Number (percent) }\end{array}$} \\
\hline White & $61(85 \%)$ & $18(78 \%)$ & $55(62 \%)$ & $26(49 \%)$ & $6(46 \%)$ \\
\hline American Indian/Alaska Native & $1(1 \%)$ & $0(0 \%)$ & $0(0 \%)$ & $0(0 \%)$ & $0(0 \%)$ \\
\hline Asian/ Asian American & $0(0 \%)$ & $1(4 \%)$ & $14(16 \%)$ & $15(28 \%)$ & $4(31 \%)$ \\
\hline Black/African American & $7(10 \%)$ & $1(4 \%)$ & $2(2 \%)$ & $2(4 \%)$ & $0(0 \%)$ \\
\hline Native Hawaiian/Pacific Islander & $1(1 \%)$ & $0(0 \%)$ & $1(1 \%)$ & $0(0 \%)$ & $0(0 \%)$ \\
\hline Not Reported/Other & $2(3 \%)$ & $3(13 \%)$ & $17(19 \%)$ & $10(19 \%)$ & $3(23 \%)$ \\
\hline \multicolumn{6}{|l|}{$\begin{array}{l}\text { Infant Ethnicity } \\
\text { Number (percent) }\end{array}$} \\
\hline Hispanic or Latinx & $5(7 \%)$ & $3(13 \%)$ & $13(15 \%)$ & $14(26 \%)$ & $0(0 \%)$ \\
\hline \multicolumn{6}{|l|}{$\begin{array}{l}\text { Infant Sex } \\
\text { Number (percent) }\end{array}$} \\
\hline Male & $33(46 \%)$ & $11(48 \%)$ & $45(51 \%)$ & $23(43 \%)$ & $9(69 \%)$ \\
\hline \multicolumn{6}{|l|}{$\begin{array}{l}\text { Maternal Education } \\
\text { Number (percent) }\end{array}$} \\
\hline High School Diploma/GED & $6(8 \%)$ & $1(4 \%)$ & $0(0 \%)$ & $1(2 \%)$ & $0(0 \%)$ \\
\hline Some College & $4(6 \%)$ & $4(18 \%)$ & $7(8 \%)$ & $4(8 \%)$ & $1(8 \%)$ \\
\hline Associate's Degree & $5(7 \%)$ & $3(13 \%)$ & $0(0 \%)$ & $5(9 \%)$ & $0(0 \%)$ \\
\hline Trade/Technical School & $0(0 \%)$ & $1(4 \%)$ & $1(1 \%)$ & $2(4 \%)$ & $0(0 \%)$ \\
\hline Bachelor's Degree & $24(33 \%)$ & $7(30 \%)$ & $30(34 \%)$ & $14(26 \%)$ & $5(38 \%)$ \\
\hline Graduate Degree & $33(46 \%)$ & $6(27 \%)$ & $51(57 \%)$ & $27(51 \%)$ & $7(54 \%)$ \\
\hline Other & $0(0 \%)$ & $1(4 \%)$ & $0(0 \%)$ & $0(0 \%)$ & $0(0 \%)$ \\
\hline \multicolumn{6}{|l|}{$\begin{array}{l}\text { Maternal Marital Status } \\
\text { Number (percent) }\end{array}$} \\
\hline Married/Domestic Partnership & $60(84 \%)$ & $19(83 \%)$ & $82(92 \%)$ & $46(87 \%)$ & $13(100 \%)$ \\
\hline Single, never married & $11(15 \%)$ & $3(13 \%)$ & $6(7 \%)$ & $7(13 \%)$ & $0(0 \%)$ \\
\hline Divorced & $1(1 \%)$ & $1(4 \%)$ & $0(0 \%)$ & $0(0 \%)$ & $0(0 \%)$ \\
\hline Not Reported & $0(0 \%)$ & $0(0 \%)$ & $1(1 \%)$ & $0(0 \%)$ & $0(0 \%)$ \\
\hline \multicolumn{6}{|l|}{$\begin{array}{l}\text { Maternal Employment Status } \\
\text { Number (percent) }\end{array}$} \\
\hline Employed for wages & $45(62 \%)$ & $16(70 \%)$ & $48(54 \%)$ & $30(57 \%)$ & $11(84 \%)$ \\
\hline Homemaker & $9(13 \%)$ & $1(4 \%)$ & $23(26 \%)$ & $8(15 \%)$ & $1(8 \%)$ \\
\hline Out of work, looking for work & $3(4 \%)$ & $2(9 \%)$ & $2(2 \%)$ & $1(2 \%)$ & $0(0 \%)$ \\
\hline Out of work, not looking for work & $11(15 \%)$ & $0(0 \%)$ & $7(8 \%)$ & $6(11 \%)$ & $0(0 \%)$ \\
\hline Self-employed & $2(3 \%)$ & $1(4 \%)$ & $6(7 \%)$ & $5(9 \%)$ & $1(8 \%)$ \\
\hline Student & $2(3 \%)$ & $3(13 \%)$ & $1(1 \%)$ & $2(4 \%)$ & $0(0 \%)$ \\
\hline Not Reported/Other & $0(0 \%)$ & $0(0 \%)$ & $2(2 \%)$ & $1(2 \%)$ & $0(0 \%)$ \\
\hline
\end{tabular}




\begin{tabular}{|c|c|c|c|c|c|}
\hline \multicolumn{6}{|l|}{$\begin{array}{l}\text { Annual household income } \\
\text { Number (percent) }\end{array}$} \\
\hline$\$ 5,001-15,000$ & $0(0 \%)$ & $2(9 \%)$ & $1(1 \%)$ & $0(0 \%)$ & $0(0 \%)$ \\
\hline$\$ 15,001-30,000$ & $3(4 \%)$ & $1(4 \%)$ & $1(1 \%)$ & $3(6 \%)$ & $0(0 \%)$ \\
\hline$\$ 30,001-60,000$ & $13(19 \%)$ & $1(4 \%)$ & $12(14 \%)$ & $7(13 \%)$ & $0(0 \%)$ \\
\hline$\$ 60,001-90,000$ & $21(29 \%)$ & $9(40 \%)$ & $6(7 \%)$ & $7(13 \%)$ & $0(0 \%)$ \\
\hline$\$ 90,001-150,000$ & $24(33 \%)$ & $7(30 \%)$ & $25(28 \%)$ & $11(21 \%)$ & $0(0 \%)$ \\
\hline More than $\$ 150,000$ & $11(15 \%)$ & $3(13 \%)$ & $44(49 \%)$ & $24(45 \%)$ & $3(23 \%)$ \\
\hline Not Reported & $0(0 \%)$ & $0(0 \%)$ & $0(0 \%)$ & $1(2 \%)$ & $10(77 \%)$ \\
\hline \multicolumn{6}{|c|}{$\begin{array}{l}\text { Children ( } \leq 17 \text { years) in the home } \\
\text { Number (percent) }\end{array}$} \\
\hline 1 & $32(44 \%)$ & $13(57 \%)$ & $50(56 \%)$ & $29(55 \%)$ & $6(46 \%)$ \\
\hline 2 & $31(43 \%)$ & $7(30 \%)$ & $28(32 \%)$ & $20(37 \%)$ & $5(39 \%)$ \\
\hline 3 & $8(12 \%)$ & $3(13 \%)$ & $8(9 \%)$ & $2(4 \%)$ & $2(15 \%)$ \\
\hline 4 & $0(0 \%)$ & $0(0 \%)$ & $1(1 \%)$ & $2(4 \%)$ & $0(0 \%)$ \\
\hline 5 & $1(0 \%)$ & $0(0 \%)$ & $2(2 \%)$ & $0(0 \%)$ & $0(0 \%)$ \\
\hline
\end{tabular}


Table S3. $\chi^{2}$ tests to compare proportional demographic makeup between final sample and participants with missing data in Study 1 and Study 2.

\begin{tabular}{|c|c|c|c|}
\hline & $\chi^{2}$ & $d f$ & $p$ \\
\hline \multicolumn{4}{|l|}{ Study 1} \\
\hline Infant race & 5.24 & 4 & .264 \\
\hline Infant ethnicity & 0.004 & 2 & .951 \\
\hline Infant sex & 0.08 & 2 & .772 \\
\hline Maternal education & 12.01 & 6 & .062 \\
\hline Maternal marital status & 0.20 & 2 & .907 \\
\hline Maternal employment status & 12.92 & 6 & .044 \\
\hline Annual household Income & 10.73 & 6 & .097 \\
\hline Children in the home & 3.70 & 4 & .448 \\
\hline \multicolumn{4}{|l|}{ Study 2} \\
\hline Infant race & 5.07 & 4 & .280 \\
\hline Infant ethnicity & 0.74 & 1 & .391 \\
\hline Infant sex & 0.01 & 1 & .926 \\
\hline Maternal education & 9.33 & 5 & .097 \\
\hline Maternal marital status & 1.45 & 2 & .485 \\
\hline Maternal employment status & 4.44 & 6 & .618 \\
\hline Annual household Income & 5.49 & 6 & .483 \\
\hline Children in the home & 3.14 & 4 & .535 \\
\hline
\end{tabular}


Table S4. Study 2 descriptive statistics for adultinitiated and infant-initiated conversations for those participants with missing vocabulary data at the 18month follow-up.

\begin{tabular}{lll}
\hline & Adult Initiated & Infant Initiated \\
& \multicolumn{2}{c}{$\begin{array}{c}\text { Mean (SD) } \\
\text { Range }\end{array}$} \\
\hline $\begin{array}{lll}\text { Total count across the } \\
\text { day }\end{array}$ & $\begin{array}{l}\text { 92.08 } \\
(41.90)\end{array}$ & $\begin{array}{l}71.69 \\
(35.06)\end{array}$ \\
& $36-167$ & $14-142$ \\
$\begin{array}{l}\text { Duration of each } \\
\text { conversation }\end{array}$ & 29.89 & 19.37 \\
(seconds) & $(40.57)$ & $(23.88)$ \\
& $1.60-567.01$ & $1.60-294.10$ \\
$\begin{array}{l}\text { Count of } \\
\text { turns in each } \\
\text { conversation }\end{array}$ & 1.78 & 1.64 \\
& $(2.04)$ & $(1.59)$ \\
$\begin{array}{l}\text { Count of adult } \\
\text { words in each } \\
\text { conversation }\end{array}$ & $1-33$ & $1-17$ \\
& 52.56 & 21.87 \\
& $(98.88)$ & $(44.01)$ \\
\hline
\end{tabular}

Note. Statistics derived from raw data. 
Table S5. Results of mixed models examining differences in features of conversations for those with missing and included data in Study 2.

\begin{tabular}{lcccccccccc}
\hline & & Duration & \multicolumn{3}{c}{ Conversational Turns } & \multicolumn{3}{c}{ Adult Words } \\
Predictors & Estimates & $C l$ & $p$ & $\begin{array}{c}\text { Incidence } \\
\text { Rate Ratios }\end{array}$ & $C l$ & $p$ & $\begin{array}{c}\text { Rate } \\
\text { Ratios }\end{array}$ & $\mathrm{Cl}$ & $p$ \\
\hline (Intercept) & 2.73 & 2.68, & $<.001$ & 1.67 & 1.61, & $<.001$ & 39.47 & 36.01, & $<.001$ \\
& & 2.78 & & & 1.73 & & & 43.26 & \\
Sample & -0.01 & -0.14, & .960 & 1.01 & 0.92, & .784 & 0.94 & 0.73, & .617 \\
& & 0.13 & & & 1.12 & & & 1.21 &
\end{tabular}

Random Effects

\begin{tabular}{llll}
$\sigma^{2}$ & 1.00 & 0.47 & 0.03 \\
$\mathrm{~T}_{00}$ & $0.05 \mathrm{ID}$ & $0.03 \mathrm{ID}$ & $0.20 \mathrm{ID}$ \\
$\mathrm{ICC}$ conditional & 0.05 & 0.05 & 0.89 \\
$\mathrm{~N}$ & $102 \mathrm{ID}$ & $102 \mathrm{ID}$ & $102 \mathrm{ID}$ \\
\hline Observations & 20,374 & 20,374 & 20,374 \\
Marginal $\mathrm{R}^{2} /$ & $0.001 /$ & $0.001 /$ & $0.002 /$ \\
Conditional $\mathrm{R}^{2}$ & 0.047 & 0.052 & 0.886 \\
\hline
\end{tabular}

Note. Model of duration is a linear mixed model utilizing the log-transformed dependent variable.

Models of conversational turns and adult words are generalized linear mixed models with

Poisson (log link) distributions. 